\title{
Color and form in successive conditional delayed discrimination shifts
}

\author{
DONALD MELTZER, JAMES J. DOHERTY, and CAI JIAN \\ Southern Illinois University, Carbondale, Illinois
}

\begin{abstract}
Eight pigeons learned a conditional delayed discrimination in which the initial schedule was a fixed ratio and the terminal segment was either FI $5 \mathrm{sec}$ or FI $25 \mathrm{sec}$. The initial to terminal stimulus sequence was color to form for 4 birds and form to color for the other 4 . The subjects were shifted to the other stimulus sequence after learning to discriminate. Color-form sequences were discriminated more accurately during both pre- and postshift sessions. However, there were no differences in rates between color-form and form-color groups during FI 5-sec components. Large differences occurred during FI 25-sec components.
\end{abstract}

A number of studies have examined the role of stimuli in delayed matching-to-sample by pigeons. It has been reported that accuracy was higher when the sample stimuli were colors and the choices were forms or line orientations, than when the reverse was true (e.g., Urcuioli \& Zentall, 1986; Wasserman, Bhatt, Chatlosh, \& Kiedinger, 1987; Zentall, Urcuioli, Jagielo, \& Jackson-Smith, 1989). Although these results are clear, it is not certain that such an effect is due to permanently greater difficulty in retaining information about forms or orientation. One obvious possibility is that pigeons do not discriminate forms as accurately as colors when they serve as sample stimuli. Experience in discriminating forms or line orientations within the context of a delayed conditional discrimination procedure may serve to reduce differences in retention.

This study examined the effect of shifting pigeons from a delayed conditional discrimination in which the initial stimulus was a form and the terminal stimulus a color, to one in which sequence was color-form. Another group of subjects was shifted from an original discrimination in which the initial stimulus was color and the terminal stimulus was form to one in which the sequence was formcolor. Hogan and Zentall (1977, Experiment 2) employed just such a design in a delayed matching task but did not report the difference, if any, between groups. We expected subjects to learn the preshift discrimination more quickly, and to achieve better asymptotic levels of discrimination when a color-form sequence was used. What would it mean if postshift performance of subjects shifted from color-form to form-color was as good as the performance of those shifted from form-color to color-form? It would support the hypothesis that form-color delayed conditional discriminations are difficult, not because pigeons find it more difficult to retain representations of forms, but because they do not discriminate forms as well as colors when forms are the initial stimuli. Having

Address correspondence and reprint requests to $D$. Meltzer, Department of Psychology, Southern Illinois University, Carbondale, IL 62901-6502. learned to discriminate forms during preshift (i.e., colorform) sessions, they would be able to discriminate formcolor sequences accurately in postshift sessions. Conversely, if postshift performance of subjects shifted from form-color to color-form was more accurate, it would support the hypothesis that representations of form were not retained as well as color, even though previous experience had ensured that subjects discriminated forms accurately.

There is a problem in determining why form samples lead to relatively poor performance of delayed matching tasks since there is no quantitative difference between correct and incorrect choices. Wasserman (1986) has described a number of experiments done with a conditional delayed successive discrimination, a procedure that may allow a clearer interpretation of the effects of different types of sample stimuli. In this method, two successive stimuli were presented, with at least two different stimulus possibilities for both the initial and the terminal stimulus. For instance, the initial stimulus might be either red or green and the terminal stimulus might be either a circle or a square. Subjects would be reinforced for responding to a circle following red but not when it followed green, and for responding to a square following green but not when it followed red. A modified version of this procedure was used in the present study.

Wasserman (1986) hypothesized that subjects solved this procedure by using retrospective, as opposed to prospective, memory. In the former case, it is assumed that the subject recalls the initial stimulus on presentation of the second stimulus and that responses are contingent on the comparison of the two. In the latter, it is assumed that the subject forms a rule as to how to respond to each terminal stimulus when the initial stimulus is presented. The retrospective memory hypothesis implies that backward associations may determine whether prior experience with form as a choice stimulus affected a subject's subsequent discrimination when form was the initial stimulus. Accuracy may have been improved if the postshift relationship between form and color that led to 
reinforcement was consistent with the pre-shift relationship that led to reinforcement. Zentall et al. (1992) have demonstrated backward associations in delayed matching, but only when the sample predicted reinforcement or nonreinforcement. Some previous studies have found evidence of weak backward associations between choice and comparison stimuli in such tasks (Gray, 1966; Rodewald, 1974; Hogan \& Zentall, 1977). No permanent effects of backward association on postshift discrimination were anticipated in this study, but consistent and inconsistent shifts were included.

\section{METHOD}

\section{Subjects}

Eight mixed-breed male pigeons, approximately 18 months old, were the subjects. Each pigeon was maintained at $85 \%$ of its free feeding weight. Experimental sessions usually were conducted 5 days a week. Water was available to the subject at all times except during the experimental session.

\section{Apparatus}

Three experimental chambers were used, each $50 \mathrm{~cm}$ long $\times 35 \mathrm{~cm}$ wide $\times 35 \mathrm{~cm}$ high. The front wall contained two response keys, $3 \mathrm{~cm}$ in diameter, located $25 \mathrm{~cm}$ above the floor and $7.5 \mathrm{~cm}$ from each sidewall. The food hopper was located behind a $5 \times 4 \mathrm{~cm}$ opening centered on the midline of the front wall. Two lamps (GE 757) mounted behind a $7.5 \times 35 \mathrm{~cm}$ piece of white Plexiglas at the top of the front wall served as a houselight. The intensity of the houselight was $14.7 \mathrm{~mL}$, as measured by an SEI photometer. An Industrial Electronics Engineers inline display unit was mounted directly behind each response key.

\section{Procedure}

All 8 pigeons were autoshaped to peck both keys. They then had three to five sessions during which the keys were transilluminated by a white light in a random sequence. Pecks on the lighted key were reinforced by a 4-sec feeder operation. Four seconds of access to the feeder served as the reinforcement for the rest of the experiment.

The subjects were divided into two groups of 4 subjects each when the experiment began. In both groups, a display initially appeared on the left key while the right key remained blank. For the subjects in the color-form group, the display on the left was a uniform field of either red or green. For subjects in the form-color group, it was either a white triangle or a white plus sign. After the subject pecked the left key six times, the display on that key was turned off and a display appeared on the right key. If the left display had been a color, the right display key was either a white triangle or a white plus; if the left display had been a form, the right display was a uniform field of either red or green. Thus there were four possible color-form (or form-color) sequences, which could be considered as cells in a $2 \times 2$ matrix: red-triangle (triangle-red), red-plus (plus-red), green-triangle (triangle-green), and green-plus (plus-green).

For the next 37 sessions, responses on the right key were reinforced after a 5-sec fixed interval (FI) when the stimulus sequences were either color A-form X and color B-form Y (or form X-color A and form
Y-color B). Color A was red and color B green for half the subjects, and the reverse was true for the remainder. Similarly, the triangle was form $\mathrm{X}$ and the plus sign form $\mathrm{Y}$ for half the subjects, and the reverse was true for the remainder. When the other two stimulus sequences, color A-form Y and color B-form X, were presented, the subjects had to allow $3 \mathrm{sec}$ to pass without pecking the right key before receiving reinforcement, a procedure commonly referred to as differential reinforcement of other behavior (DRO). Following reinforcement there was a 20-sec intertrial interval, during which no stimulus was present on either key. A session ended when a subject had received 48 reinforcements. However, the pigeons often responded at high rates during the DRO components, and sessions frequently lasted for longer than $3 \mathrm{~h}$. In order to avoid such excessive session durations, the procedure was changed so that the DRO schedule was replaced by an FI-25 sec schedule.

The response rates during the first $5 \mathrm{sec}$ of the 25 -sec intervals were compared with the response rates during the 5 -sec intervals. Control by the two-key stimulus sequence was demonstrated by higher response rates during the FI 5-sec component. This procedure continued for an additional 37 sessions and provided the preshift data analyzed in this paper.

The subjects were then switched to a new procedure, in which a trial began with a stimulus presented on the right key. Each group was also subdivided into consistent and inconsistent groups as described in both Table 1 and the following paragraph.

After the subject completed six responses on the right key, the stimulus on the right was turned off and a stimulus appeared on the left key. Responses to the left key were reinforced after the display on the left had been on for either 5 or $25 \mathrm{sec}$. The stimuli on the keys were always one of the stimuli that had appeared on the same key prior to the shift. During preshift sessions, subjects in the color-form group had been reinforced for right-key responses after $5 \mathrm{sec}$ when color $\mathrm{A}-$ form $\mathrm{X}$ and color B-form $\mathrm{Y}$ had been the left-right stimulus sequence; now, in the consistent condition during postshift sessions, they were reinforced for left-key responses after $5 \mathrm{sec}$ when the right-left sequence was form $\mathrm{X}$-color $\mathrm{A}$ and form $\mathrm{Y}$-color $\mathrm{B}$. The procedure for subjects in the inconsistent group was the same during preshift sessions, but during postshift sessions they were reinforced for a right-key response after $5 \mathrm{sec}$ when the sequences were either form $\mathrm{X}$-color $\mathrm{B}$ or form $\mathrm{Y}$-color $\mathrm{A}$ and after $25 \mathrm{sec}$ when the sequences were form $\mathrm{X}$-color $\mathrm{A}$ or form $\mathrm{Y}$-color A. There were a total of 22 postshift sessions.

The subjects for which the preshift stimulus sequence was form-color were also separated into consistent and inconsistent groups, and their postshift stimulus sequences were color-form.

\section{RESULTS}

Analysis of response rates during preshift sessions showed no significant differences in responses on the left key. Analysis of right-key responses showed several significant differences. The subjects responded at higher rates during FI 5-sec intervals than during the first $5 \mathrm{sec}$ of an FI 25 -sec schedule. The difference was significant $[F(1,4)=107.8, p<.01]$ and showed that subjects had learned the delayed conditional discrimination.

However, subjects that had to discriminate between forms as part of a color-form sequence showed a greater

Table 1

The Stimulus Sequences for Subjects in Different Groups During Both Preshift and Postshift Sessions

\begin{tabular}{|c|c|c|c|c|c|c|c|c|}
\hline \multirow[b]{3}{*}{ Interval } & \multicolumn{4}{|c|}{ Consistent } & \multicolumn{4}{|c|}{ Inconsistent } \\
\hline & \multicolumn{2}{|c|}{ Color-Form } & \multicolumn{2}{|c|}{ Form-Color } & \multicolumn{2}{|c|}{ Color-Form } & \multicolumn{2}{|c|}{ Form-Color } \\
\hline & Preshift & Postshift & Preshift & Postshift & Preshift & Postshift & Preshift & Postshift \\
\hline $\begin{array}{l}\text { FI } 5 \\
\text { FI } 25 \\
\end{array}$ & $\begin{array}{l}\text { AX,BY } \\
\text { AY,BX }\end{array}$ & $\begin{array}{l}\mathrm{XA}, \mathrm{YB} \\
\mathrm{YA}, \mathrm{XB} \\
\end{array}$ & $\begin{array}{l}\mathrm{XA}, \mathrm{YB} \\
\mathrm{YA}, \mathrm{XB}\end{array}$ & $\begin{array}{l}\text { AX,BY } \\
\text { AY,BX }\end{array}$ & $\begin{array}{l}\text { AX,BY } \\
\text { AY,BX }\end{array}$ & $\begin{array}{l}\text { YA,XB } \\
\text { BY,XA } \\
\end{array}$ & $\begin{array}{l}\mathrm{XA}, \mathrm{YB} \\
\mathrm{YA}, \mathrm{XB} \\
\end{array}$ & $\begin{array}{l}\text { YA, XB } \\
\text { AX, BY }\end{array}$ \\
\hline
\end{tabular}

Note-Colors are represented by the letters $A$ and $B$. Forms are represented by the letters $X$ and $Y$. For 1 subject in each subgroup, color A was red and color B green. The reverse was true for the other subject. Similarly, form $\mathrm{X}$ was a triangle and form $\mathrm{Y}$ a plus for 1 subject and the reverse was true for the other subject. 
differential than did those that discriminated between colors as part of a form-color sequence. These data are shown for each session in Figure 1, and this interaction between stimulus conditions and reinforcement schedule was significant $[F(1,4)=48.14, p<.01]$. Tests of simple main effects showed that the subjects made more responses during the FI 5-sec component regardless of whether the stimulus sequence was color-form $[F(1,4)=$ $252.24, p<.01]$ or form-color $[F(1,4)=9.97, p<$ $.05]$. Nevertheless, there was a difference in the rate at which the subjects responded during different reinforcement schedules as a function of the stimulus sequence. The subjects in the color-form group made more responses during the FI 5-sec component than did the subjects in the form-color group $[F(1,4)=18.26, p<.05]$, and response rates during the first $5 \mathrm{sec}$ of FI 25 -sec intervals were significantly lower for the subjects in the color-form group than for those in the form-color group $[\mathrm{F}(1,4)=71.43, p<.01]$.

The difference between response rates during FI $5 \mathrm{sec}$ and FI $25 \mathrm{sec}$ increased over sessions, and this interaction was also significant $[F(36,144)=4.79, p<.05]$. Finally, analyses showed that the difference between rates in FI $5 \mathrm{sec}$ and the first $5 \mathrm{sec}$ of FI 25-sec components increased more rapidly over sessions when the stimulus sequence was color-form rather than form-color $[F(36,144)=2.16$, $p<.05]$. This interaction between schedule, stimulus condition and sessions is shown in Figure 1. However, the interaction between schedule and stimulus conditions failed to reach significance during any single session. The only significant main effect was the difference between rates during FI $5 \mathrm{sec}$ and the first $5 \mathrm{sec}$ of FI $25 \mathrm{sec}$. The difference was significant in all sessions from the sixth to the final preshift session. Figure 1 also shows that mean rate differences between subjects in the color-form and

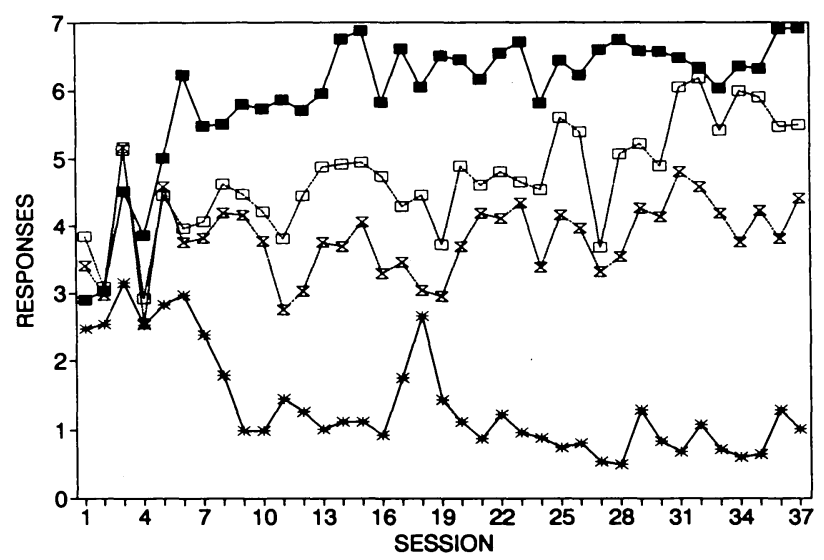

$\rightarrow-F I 5 F / C \rightarrow F / 5 C / F \rightarrow-F I 25$ F/C - - FI25 C/F

Figure 1. Mean number of responses during the first $5 \mathrm{sec}$ of FI 25-sec intervals and during FI 5-sec intervals in preshift sessions. Data are from the terminal color segment for subjects in the form-color (F/C) condition and the terminal form segment for subjects in the color-form (C/F) condition. form-color groups were greater during the first $5 \mathrm{sec}$ of FI 25-sec intervals than during FI 5-sec intervals.

Because the interaction among sessions, stimulus conditions, and schedule was significant, an additional analysis of data from the last five preshift sessions was performed. As expected, the mean number of responses during FI $5 \mathrm{sec}$ exceeded the mean number during the initial $5 \mathrm{sec}$ of FI $25 \mathrm{sec}$, and the difference was significant $[F(1,4)=$ $94.41, p<.01]$. It is also apparent from Figure 1 that although responses during FI $5 \mathrm{sec}$ were similar regardless of the stimulus sequence, rates during the first $5 \mathrm{sec}$ of FI $25 \mathrm{sec}$ were much lower when the sequence was color-form rather than form-color. This interaction was significant $[F(1,4)=30.03, p<.01]$, and tests of simple main effects confirmed that the difference between FI 5 -sec rates was not significant but that the difference between FI 25-sec rates was $[F(1,4)=8.54, p<.05]$.

Data from postshift sessions were analyzed in several different ways. In order to determine whether there were transient effects of consistent as opposed to inconsistent shifts, an analysis of responses during the first postshift session was performed. No significant effects were found.

Analysis of response rates during all postshift sessions showed that subjects learned the new discrimination and responded at higher rates during the FI 5-sec interval than during the first $5 \mathrm{sec}$ of each FI 25 -sec interval. The difference was significant $[F(1,4)=136.66, p<.01]$, but the magnitude of the difference depended on the stimulus sequence. Differences were greater when subjects responded to a color-form sequence than to a form-color sequence. This interaction between reinforcement schedule and stimulus sequence was significant $[F(1,4)=55.90$, $p<.01]$. Tests of simple main effects confirmed that response rates during FI $5 \mathrm{sec}$ were significantly higher in both the color-form $[F(1,4)=183.69, p<.01]$ and for$\mathrm{m}$-color $[F(1,4)=8.88, p<.05]$ conditions. They also showed that subjects made more responses during the FI 5 -sec component when they experienced a color-form as opposed to a form-color sequence $[F(1,4)=10.67, p<$ $.05]$ and also made fewer responses during the first $5 \mathrm{sec}$ of FI $25 \mathrm{sec}$ in the color- form condition $[F(1,4)=53.39$, $p<.01]$. Figure 2 also shows that rate differences between the subjects in the color-form and form-color groups were greater during the first $5 \mathrm{sec}$ of FI 25-sec intervals than during FI 5-sec intervals, as was also true in preshift sessions.

The difference between response rates in FI $5 \mathrm{sec}$ and the first $5 \mathrm{sec}$ of FI 25 -sec intervals increased over sessions, as is shown in Figure 2, and this interaction was significant $[F(21,84)=16.21, p<.01]$. Analyses of simple main effects showed that rates during FI $5 \mathrm{sec}$ were significantly higher in all but the first four postshift sessions. As was also the case in preshift sessions, the difference between rates in the two reinforcement schedules changed over sessions as a function of the stimulus conditions. Figure 2 also shows that rates during the FI 5-sec component increased more rapidly over sessions when the stimulus sequence was color-form. Rates during the FI 25sec component decreased more rapidly over sessions when 


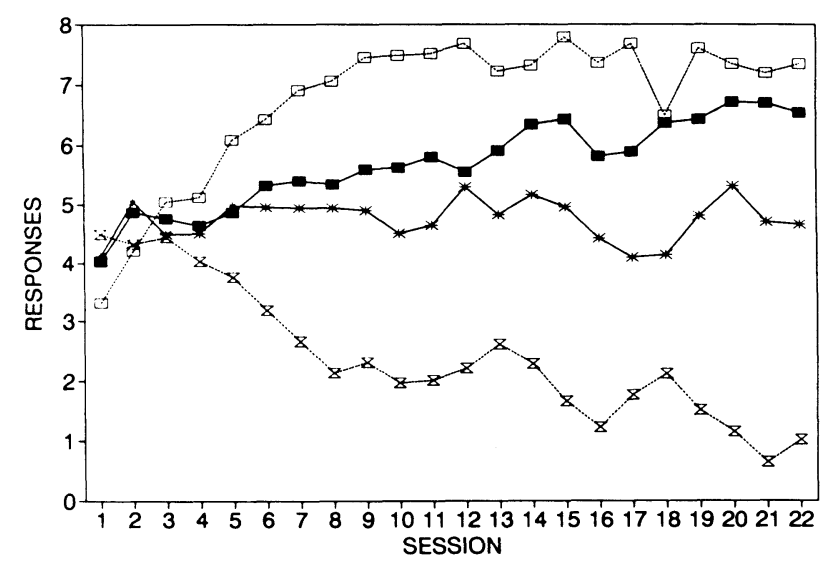

$-\mathrm{FI} 5 \mathrm{~F} / \mathrm{C} \uplus \mathrm{FI} 5 \mathrm{C} / \mathrm{F} \rightarrow \mathrm{FI} 25 \mathrm{~F} / \mathrm{C}-\mathrm{z}-\mathrm{FI} 25 \mathrm{C} / \mathrm{F}$

Figure 2. Mean number of responses during the first $5 \mathrm{sec}$ of FI 25-sec intervals and during FI 5-sec intervals in postshift sessions. Data are from the terminal color segment for subjects in the form-color (F/C) condition who had experienced the color-form condition during preshift sessions. Similarly, data are from the terminal form segment for subjects in the color-form (C/F) condition who had experienced the form-color sequence during preshift sessions.

the sequence was color-form. This interaction between schedule, sessions, and stimulus sequence was significant $[F(21,84)=6.11, p<.01]$.

There was no difference between the postshift performance of subjects who underwent consistent as opposed to inconsistent shifts, nor was there any significant interaction involving type of shift. In other words, no evidence supporting bidirectional association was found.

Finally, since sessions interacted significantly with both schedule and stimulus condition, data from the last five postshift sessions were analyzed. The subjects responded at significantly higher rates during FI 5-sec intervals than they did during the first $5 \mathrm{sec}$ of each FI 25 -sec component $[F(1,4)=70.45, p<.01]$. However, just as in the last five preshift sessions, response rate differences were greater for subjects exposed to a color-form sequence than for those exposed to a form-color sequence. The interaction was significant $[F(1,4)=19.49, p<.05]$. Tests of simple main effects confirmed that FI 5-sec rates were significantly higher than FI 25-sec rates, regardless of the stimulus sequence. However, as was the case in the last five preshift sessions, there was no significant difference between rates in the FI 5-sec component, but subjects who experienced a color-form sequence made significantly fewer responses during the first $5 \mathrm{sec}$ of the FI 25 -sec component $[F(1,4)=$ $27.61, p<.01]$.

\section{DISCUSSION}

The question that prompted this study was whether experience with form as a terminal stimulus would improve subjects' performances when forms served as initial stimuli. The answer was clearly negative. Apparently, retention of color was better than retention of form regardless of prior experience.

The relatively poor performance of subjects on postshift discriminations of form-color sequences probably was not a consequence of poor discriminations of forms as opposed to colors. The same forms were used as the terminal components of color-form sequences prior to the shift, and subjects discriminated between them with great accuracy. For the same reason, it appears that superior performance with the color-form sequence during preshift sessions has little, if anything, to do with the greater discriminability of colors. The same colors served as terminal segment stimuli during postshift sessions, and the same subjects failed to discriminate them very well. Relatively poor discrimination between formcolor sequences in preshift sessions was followed by highly accurate colorform discriminations in postshift sessions.

It may be argued that retrospective processes could account for the results more easily than prospective models. If discriminability of forms and colors was not affected by whether they were initial or terminal segment stimuli, there is no obvious reason to assume that it would be more difficult for a subject to form or retain a prospective code based on either type of stimulus. On the other hand, a retrospective model could easily account for the difference if retention of forms is assumed to be more difficult. The obvious prospective hypothesis is that discriminability bears little relationship to the ease with which a stimulus is coded for retention.

The fact that rate differences during stable performances were significantly different at the beginning of FI 25 -sec intervals but not during FI 5 -sec intervals showed that superior retention of color did not produce symmetrical effects. One possible explanation for the difference is a ceiling effect on the mean number of responses a subject could make during an FI 5-sec interval, but the observed mean number of 7.2 responses per interval was well below maximum rates commonly observed. What these data did show was that rate differences during the terminal segments were a function of reinforcement probabilities during those segments. Control by preceding stimuli was weaker in the presence of current stimuli signaling short delays to reinforcement.

Finally, there was no evidence of backward or bidirectional association. A retrospective model would seem to imply that a current stimulus causes the subject to recall a preceding stimulus. In that case, consistent shifts should have led to superior postshift performance than should inconsistent shifts. However, the backward associations may have been so transient that they did not persist even over the first postshift session.

\section{REFERENCES}

Gray, L. (1966). Backward association in pigeons. Psychonomic Science, 4, 333-334.

Hogan, D. E., \& Zentall, T. R. (1977). Backward associations in the pigeon. American Journal of Psychology, 90, 3-15.

Rodewald, H. K. (1974). Symbolic matching to sample by pigeons. Psychological Reports, 34, 987-990.

Urcuiol, P. J., \& Zentall, T. R. (1986). Retrospective coding in pigeons' delayed matching-to-sample. Journal of Experimental Psychology: Animal Behavior Processes, 12, 69-77.

Wasserman, E. A. (1986). Prospection and retrospection as processes of animal short-term memory. In D. F. Kendrick, M. E. Rilling, \& M. R. Denny (Eds.), Theories of animal memory (pp. 53-75). Hillsdale, NJ: Erlbaum.

Wasserman, E. A., Bhatt, R. S., Chatlosh, D. L., \& Kiedinger, R. E. (1987). Discrimination of and memory for dimension and value information by pigeons. Learning \& Motivation, 13, 417-433.

Zentall, T. R., Sherburne, L. M., \& Steirn, J. N. (1992). Development of excitatory backward associations during the establishment of forward associations in a delayed conditional discrimination by pigeons. Animal Learning \& Behavior, 20, 199-206.

Zentall, T. R., Urcuiou, P. J., Jagielo, J. A., \& Jackson-Smith, P. (1989). Interaction of sample dimension and sample-comparison mapping on pigeons' performance of delayed conditional discriminations. Animal Learning \& Behavior, 17, 172-178.

(Manuscript received November 16, 1992.) 